\title{
Identification of Carbonyl Reductase 1 as a Resveratrol-Binding Protein by Affinity Chromatography Using 4'-Amino-3,5-dihydroxy-trans-stilbene
}

\author{
Yuta ITO ${ }^{1}$, Takakazu MITANI $^{1}$, Naoki HARADA ${ }^{1}$, Atsushi IsAYAMA ${ }^{1}$, Shinji TANIMORI ${ }^{1}$, \\ Shigeo TAKENAKA ${ }^{2}$, Yoshihisa NAKANO ${ }^{3}$, Hiroshi INUI ${ }^{1}$ and Ryoichi YAMAJI ${ }^{1, *}$ \\ ${ }^{1}$ Division of Applied Life Sciences, and ${ }^{2}$ Division of Veterinary Science, Graduate School of Life and Environ- \\ mental Sciences, Osaka Prefecture University, Sakai, Osaka 599-8531, Japan \\ ${ }^{3}$ Osaka Women's Junior College, Fujiidera, Osaka 583-8558, Japan
}

(Received February 27, 2013)

\begin{abstract}
Summary The mechanisms by which resveratrol (3,4',5-trihydroxy-trans-stilbene) elicits diverse health benefits remain unclear because the intracellular target molecules of resveratrol are poorly defined. We screened resveratrol-binding proteins from lysates of MCF-7 breast cancer cells using resveratrol-affinity resin, which was constructed by immobilizing 4'-amino-3,5-dihydroxy-trans-stilbene on activated CH-Sepharose. On SDS-PAGE, two bands were detected as proteins that specifically bound to the resveratrol-affinity resin. One of these, a 30-kDa protein, was identified as human carbonyl reductase 1 (CBR1) by hybrid linear ion trap/time-of-flight mass spectrometry. Similarly, recombinant CBR1 bound to the resveratrol-affinity resin in the absence of resveratrol, but not in the presence of resveratrol. Among its activities, CBR 1 catalyzes a NADPH-dependent reduction of the anticancer drug doxorubicin to the cardiotoxin doxorubicinol. The effects of doxorubicin on viability of MCF-7 cells were enhanced by resveratrol, 3,5-dihydroxy-4'-methoxy-trans-stilbene, 3,4'-dihydroxy5-methoxy-trans-stilbene, and 4'-amino-3,5-dihydroxy-trans-stilbene at concentrations of 1 and $10 \mu \mathrm{M}$. Resveratrol and these derivatives inhibited CBR1 activities to a similar degree at concentrations of 100 and $200 \mu \mathrm{M}$. However, 3,5-dimethoxy-4'-hydroxy-trans-stilbene and $m$-hydroquinone had no influence on doxorubicin cytotoxicity or CBR1 activity. Resveratrol inhibited CBR1 activity through an apparent mix of competitive $(\mathrm{Ki}=55.8 \mu \mathrm{M})$ and noncompetitive $(\alpha \mathrm{Ki}=164 \mu \mathrm{M} ; \alpha=2.98)$ inhibition kinetics. These results indicate that (i) resveratrol enhances the cytotoxic effects of doxorubicin on MCF-7 cells; (ii) the moiety that contains the 3,5-dihydroxyl groups of resveratrol, but not the $m$-hydroquinone structure alone, is required to bind CBR1; and (iii) resveratrol acts as a mixed-type inhibitor of CBR1 activity on doxorubicin.
\end{abstract}

Key Words resveratrol, carbonyl reductase 1, affinity chromatography, doxorubicin, breast cancer cells

Resveratrol (3,4',5-trihydroxy-trans-stilbene) is a phytopolyphenol that is present in a variety of edible plant products including berries and peanuts $(1,2)$. Because resveratrol is abundant in grape skin, its highest concentrations are found in grape products such as grape juice and wine, particularly red wine (3). For plants themselves, resveratrol is a natural phytoalexin produced in response to adverse conditions such as environmental stress or fungal infection (4). On the other hand, for humans, resveratrol exerts preventive effects against pathological processes such as inflammation (5), atherosclerosis (6), cardiovascular disease (7), and tumorigenesis in a variety of cancers including breast cancer

*To whom correspondence should be addressed.

E-mail: yamaji@biochem.osakafu-u.ac.jp

Abbreviations: CBR1, carbonyl reductase; ER, estrogen receptor.
(8). Furthermore, resveratrol enhances the cytotoxic effect of doxorubicin on the growth of human breast cancer MCF-7 cells (9). However, the mechanisms by which resveratrol provides such diverse health benefits remain unclear because few of the intracellular target molecules of resveratrol have been identified.

Resveratrol has two kinds of phenols. Some structural features of resveratrol such as the number and the position of hydroxyl groups play an important role in its inhibitory effects on various enzymes $(10,11)$. The hydroxyl group in the $4^{\prime}$ position of resveratrol with stereoisomery in the trans-conformation $\left(4^{\prime}\right.$-hydroxystyryl moiety) is required for binding to estrogen receptor (ER) $\alpha$ and anti-proliferative activity against MCF-7 cells (12). Furthermore, 4-hydroxy-trans-stilbene, or perhaps just its 4-hydroxystyryl moiety, up-regulates the expression of cyclins $\mathrm{A}, \mathrm{E}$, and $\mathrm{B}_{1}$ (13). On the other hand, the $m$-hydroquinone moiety of resveratrol (resorcinol) is the 
minimum structure necessary to inactivate cyclooxygenase-1 (14).

Quinone reductase 2 (15), glutathione sulfotransferase- $\pi$, and $\operatorname{ER} \beta$ (16) have been identified as resveratrolbinding proteins by resveratrol-affinity chromatography. Resveratrol is immobilized on epoxy-activated agarose through any one of three hydroxyl groups. Thus, the resveratrol-specific bio-affinity strategy provides no information about which hydroxyl groups of resveratrol are required for the binding of resveratrol-binding proteins to the affinity resin. The affinity resin is useful as a tool to search for resveratrol-binding proteins, which are required for at least the $4^{\prime}$-hydroxyl group of resveratrol, because $\mathrm{ER} \beta$, which is in the same protein family as $\operatorname{ER} \alpha$, binds to the affinity resin. However, it remains unclear whether the affinity resin is useful as a tool to search for resveratrol-binding proteins, which are required for the hydroxyl group of 3 or 5 position of resveratrol. In the present study, we prepared a resveratrol-affinity Sepharose resin by immobilizing $4^{\prime}$-amino3,5-dihydroxy-trans-stilbene on activated CH-Sepharose through its $4^{\prime}$-amino group and identified carbonyl reductase 1 (CBR1) as a resveratrol-binding protein.

CBR1 metabolizes physiological (endogenous) substrates such as prostaglandin E2 (17) and S-nitrosoglutathione (18) or xenobiotic (exogenous) substrates such as anthracycline anticancer drugs (doxorubicin and daunorubicin) (19). Doxorubicin is used to treat many cancers including breast cancer because it results in DNA damage by intercalating the DNA base pairs of the double helix. However, CBR1 catalyzes the reduction of doxorubicin to doxorubicinol, which is less potent in killing cancer cells and induces chronic cardiotoxicity. Some tumor cells acquire resistance to doxorubicin through the increased expression of CBR1 (20), indicating that resistance and toxicity limit the effectiveness of doxorubicin. Therefore, we further investigated the effects of resveratrol and its derivatives on the cytotoxicity of doxorubicin in MCF-7 cells and CBR1 activity using doxorubicin as a substrate and characterized the kinetics of resveratrol as a CBR 1 inhibitor.

\section{Materials and Methods}

Reagents. Resveratrol, 3,5-dimethoxy-4'-hydroxytrans-stilbene, and 3,4'-dihydroxy-5-methoxy-trans-stilbene were obtained from Tokyo Chemical Industry Co., Ltd. (Tokyo, Japan). 4'-Amino-3,5-dihydroxy-trans-stilbene was synthesized according to the method of Sun et al. (21), and 3,5-dihydroxy-4'-methoxy-trans-stilbene was synthesized according to the method of Paul et al. (22).

Cell culture. Human breast cancer MCF-7 cells were obtained from the RIKEN BioResource Center (Ibaraki, Japan). The cells were cultured in growth medium (Dulbecco's modified Eagle's medium-high glucose $(4.5 \mathrm{~g} / \mathrm{L}$ glucose) supplemented with $10 \%$ fetal bovine serum, $100 \mathrm{U} / \mathrm{mL}$ penicillin and $100 \mu \mathrm{g} / \mathrm{mL}$ streptomycin) at $37^{\circ} \mathrm{C}$ in a $5 \% \quad \mathrm{CO}_{2} / 95 \%$ air atmosphere at $100 \%$ humidity.

Preparation of resveratrol-affinity resin. Activated
CH-Sepharose (1 g freeze-dried powder; GE Healthcare, Uppsala, Sweden) was activated by $1 \mathrm{~mm} \mathrm{HCl}$ and incubated with 4'-amino-3,5-dihydroxy-trans-stilbene $(25 \mathrm{mg})$ in coupling buffer $\left(0.1 \mathrm{M} \mathrm{NaHCO}_{3}, 0.5 \mathrm{M} \mathrm{NaCl}\right.$, and $50 \%$ ethanol) at $4^{\circ} \mathrm{C}$ for $4 \mathrm{~h}$. The Sepharose resin which was washed several times with coupling buffer and incubated with $1 \mathrm{M}$ monoethanolamine at $4^{\circ} \mathrm{C}$ for $1 \mathrm{~h}$, followed by washing with coupling buffer, was termed resveratrol-affinity resin.

Identification of resveratrol-binding proteins. MCF-7 cells were sonicated in lysis buffer (20 mM Hepes$\mathrm{NaOH}, \mathrm{pH}$ 7.5, containing $150 \mathrm{~mm} \mathrm{NaCl}, 1 \mathrm{~mm}$ EDTA, 1\% Nonidet P-40, $1 \mathrm{~mm}$ dithiothreitol, 10\% glycerol, $1 \mathrm{~mm}$ phenylmethylsulfonyl fluoride, $10 \mu \mathrm{g} / \mathrm{mL}$ of leupeptin, and $1 \mu \mathrm{g} / \mathrm{mL}$ of aprotinin) and centrifuged at $20,000 \times g$ at $4^{\circ} \mathrm{C}$ for $10 \mathrm{~min}$. The supernatant was used as a crude extract throughout the experiments. The crude extract ( $2 \mathrm{mg}$ protein) was incubated with resveratrol-affinity resin ( $100 \mu \mathrm{L} ; 50 \%$ slurry) in the presence or absence of resveratrol $(1 \mathrm{mM})$, and proteins bound to the resin were subjected to SDS-PAGE, followed by silver staining. The selected gel bands, which were not detected in the presence of resveratrol, were subjected to in-gel trypsin digestion as described previously (23) and analyzed with an ion trap/time-of-flight mass spectrometer (LCMS IT-TOF, Shimadzu Corp., Kyoto, Japan). Data were further analyzed by the Mascot MS/MS Ions Search algorithm to identify proteins corresponding to the bands.

Recombinant CBR 1 protein. Human CBR 1 cDNA was amplified by nested PCR and cloned into pCR2.1-TOPO vector, followed by sub-cloning into pET30 vector. The resultant pET30-CBR1 was transformed into Escherichia coli BL21(DE3), and the C-terminal His-tagged recombinant CBR 1 was purified using Ni-Sepharose FF (GE Healthcare). The purified protein, which was detected as a single band by SDS-PAGE, was used throughout the experiments.

CBR1 activity. Purified recombinant CBR1 was prepared as described above. For the inhibitory effects of resveratrol and its derivatives on CBR 1 activity, the enzyme activities were measured at $37^{\circ} \mathrm{C}$ for $10 \mathrm{~min}$ in $100 \mu \mathrm{L}$ of reaction mixture containing $100 \mathrm{mM}$ sodium phosphate buffer, pH 7.0, $100 \mu \mathrm{M}$ NADPH, $500 \mu \mathrm{M}$ doxorubicin, enzyme ( $4 \mu \mathrm{g}$ protein), and resveratrol or its derivatives $(100$ and $200 \mu \mathrm{M})$. For the kinetics studies, the assay reaction was performed in $100 \mu \mathrm{L}$ of reaction mixture containing $100 \mathrm{~mm}$ sodium phosphate buffer, pH 7.0, $100 \mu \mathrm{M}$ NADPH, doxorubicin (0-500 $\mu \mathrm{M})$, enzyme (4 $\mathrm{g}$ protein), and resveratrol $(0-200 \mu \mathrm{M})$. The measured rates for $10 \mathrm{~min}$ were in the linear range of the enzyme kinetic curve. The reaction was stopped by the addition of $100 \mu \mathrm{L}$ of ice-cold ethanol on ice, followed by the further addition of $10 \mu \mathrm{L}$ of $250 \mu \mathrm{M}$ daunorubicin as an internal standard and vortex mixing. The mixture was centrifuged for $20,000 \times g$ at $4^{\circ} \mathrm{C}$ for $5 \mathrm{~min}$, and the supernatant was injected into a HPLC system (Nihonbunkoh, Tokyo, Japan) with a fluorescence detector (excitation at $480 \mathrm{~nm}$ and emission $560 \mathrm{~nm}$ ). Separation was performed on a reverse phase 
column (C18 AR II, 4.6 mm I.D.-150 mm; Nakalai Tesque, Inc., Kyoto, Japan), with a mobile phase (50 mM monosodium phosphate buffer/acetonitrile $[(\mathrm{v} / \mathrm{v}) 3: 1]$ $(\mathrm{pH} 4.0)$ ) at a flow rate of $0.5 \mathrm{~mL} / \mathrm{min}$. A calibration curve with doxorubicinol standard (10-400 pmol) was prepared.

Western blot. Crude extract (2 mg protein) or recombinant CBR1 (10 $\mu \mathrm{g}$ protein) was incubated with resveratrol-affinity resin (100 $\mu \mathrm{L} ; 50 \%$ slurry) in the presence or absence of resveratrol or quercetin, and proteins bound to the resin were subjected to SDS-PAGE, followed by Western blot analysis with anti-CBR1 antibody (Aviva Systems Biology, San Diego, CA). Immunoreactive proteins were incubated with horseradish peroxidase-conjugated goat anti-rabbit antibody and reacted with Immobilon Western Chemiluminescent HRP Substrate (Millipore, Billerica, MA), followed by detection with an LAS4000 imaging system (GE Healthcare).

Viability. MCF-7 cells $\left(2.5 \times 10^{3}\right.$ cells/well $)$ were plated in a 48 -well plate and cultured in growth medium for $24 \mathrm{~h}$, followed by incubation in the presence of vehicle (DMSO), doxorubicin (0-10 nM), or resveratrol or its derivatives $(0-10 \mu \mathrm{M})$ for $72 \mathrm{~h}$. Cells were further incubated in growth medium without phenol red for $1 \mathrm{~h}$, followed by treatment with Alamar Blue reagent at a final concentration of 5\% (Alamar Bioscience, Chicago, IL) for an additional $4 \mathrm{~h}$ according to the manufacturer's instructions. The fluorometric assay (excitation at $544 \mathrm{~nm}$ and emission $590 \mathrm{~nm}$ ) was performed using Fluoroskan Ascent FL (Thermo Fisher Scientific, Waltham, MA).

Statistical analysis. The effects of resveratrol and its derivatives on cell viability and CBR1 activity were evaluated by two-way analysis of variance with Tukey's post hoc testing. Statistical analysis was performed using JMP statistical software version 8.0.1 (SAS Institute, Cary, NC). Data are expressed as mean \pm SD, and differences were considered statistically significant at a $p$ value of $<0.05$.

\section{Results}

To screen proteins that interact with one or both of the hydroxyl groups in the $m$-hydroquinone moiety of resveratrol, 4'-amino-3,5-dihydroxy-trans-stilbene was synthesized according to the method of Sun et al. (21) and was immobilized on Sepharose through its amino group (Fig. 1A). Proteins in MCF-7 cell lysates were incubated with the resin in the presence or absence of resveratrol, and proteins bound to the resin were analyzed by SDS-PAGE, followed by silver staining (Fig. 1B). Two bands (arrows in Fig. 1B) were detected as proteins that specifically bound to resveratrol. Peptide sequences predicted by the mass spectrometric analysis were blasted against the protein databases, and nine peptides from one (lower arrow in Fig. 1B) of the two bands matched CBR1 (Fig. 1C). The sequence coverage was $36 \%$. Western blot analysis with anti-CBR 1 antibody showed that CBR 1 bound to the resveratrol-affinity resin in the absence of resveratrol, but not in the presence of resveratrol (Fig. 1D). Furthermore, to determine
(A)

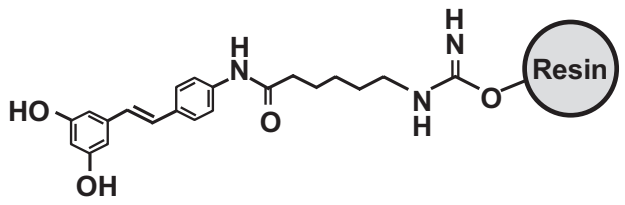

(B)

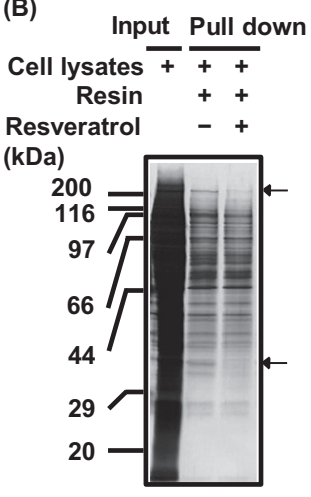

(C)

\begin{tabular}{ll} 
CBR1 peptides \\
Positions & Amino acid sequences \\
\hline $16-23$ & GIGLAIVR \\
$28-38$ & LFSGDVVTAR \\
$43-58$ & GQAAVQQLQAEGLSPR \\
$72-78$ & ALRDFLR \\
$120-134$ & DVCTELLPLIKPQGR \\
$135-145$ & VVNVSSIMSVR \\
$187-198$ & EGWPSSAYGVTK \\
$199-206$ & IGVYVLSR \\
$221-232$ & ILLNACCPGWVR
\end{tabular}

(D)

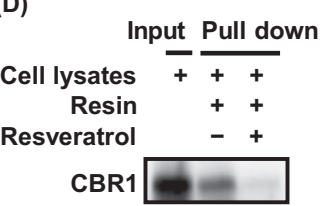

(E)

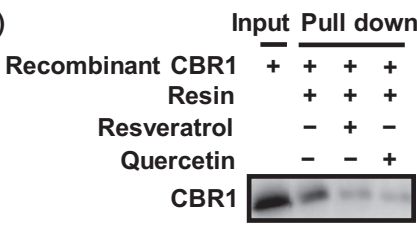

Fig. 1. Identification of CBR1 as a resveratrol-affinity protein. (A) Schematic representation of the resveratrol-immobilized resin (resveratrol-affinity Sepharose) constructed in this study. (B) MCF-7 cell lysates were incubated with the resveratrol-affinity resin in the presence or absence of resveratrol. Proteins bound to the resin were subjected to SDS-PAGE, followed by silver staining. Arrows indicate protein bands that were not detected in the presence of resveratrol. (C) Amino acid sequences of peptide fragments were obtained with an ion trap/time-of-flight mass spectrometer and Mascot MS/MS ion Search algorithm. (D) MCF-7 cell lysates were incubated with the resveratrol-affinity resin in the presence or absence of resveratrol, followed by Western blot analysis with anti-CBR1 antibody. (E) Recombinant CBR1 was incubated with the resveratrol-affinity resin in the presence or absence of resveratrol or quercetin, followed by Western blot analysis with anti-CBR1 antibody.

whether CBR1 directly binds to resveratrol, a C-terminal His-tagged recombinant CBR1 protein was purified and incubated with the resin in the presence or absence of resveratrol. The binding of recombinant CBR1 protein to the resin was inhibited in the presence of resveratrol (Fig. 1E). When the recombinant CBR1 protein was incubated with the resin in the presence of quercetin, the binding of CBR1 to the resin was inhibited. These results indicate that resveratrol physically interacts with CBR 1 and suggest that the interaction of quercetin with CBR1 occurs at the same site as the resveratrol-binding site on CBR1. On the other hand, although another resveratrol-affinity resin was reported to bind $\operatorname{ER} \beta$ (16), a Western blot of the proteins bound to our resin using anti-ER $\beta$ antibody detected no bands (data not shown). 
<smiles>[R6]C1CCCC1</smiles><smiles>COc1cc(O)cc(/C=C/c2ccc(O)cc2)c1</smiles><smiles>COc1ccc(/C=C/c2cc(O)cc(O)c2)cc1</smiles><smiles>Nc1ccc(/C=C/c2cc(O)cc(O)c2)cc1</smiles>

(B)

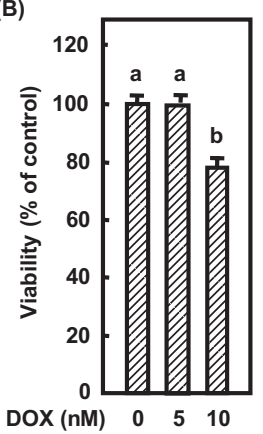

(C)

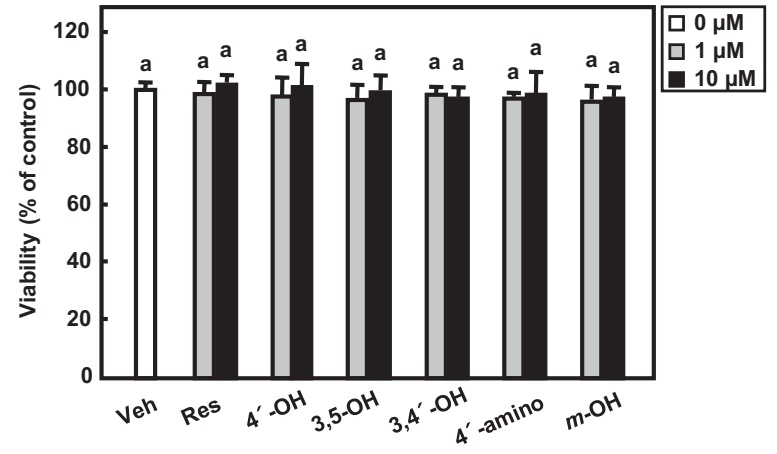

(D)

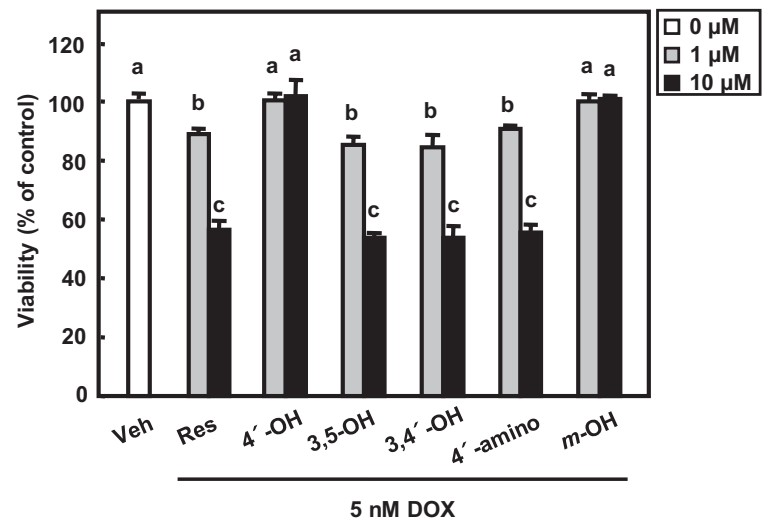

Fig. 2. Enhancing effects of resveratrol and its derivatives on cytotoxicity of doxorubicin in MCF-7 cells. (A) Chemical structures. (B) MCF-7 cells were cultured in the presence or absence of doxorubicin (DOX) (5 or $10 \mathrm{nM}$ ), and cell viabilities were determined. (C) MCF-7 cells were cultured in the presence of vehicle (Veh), 3,4',5-trihydroxy-trans-stilbene (Res), 3,5-dimethoxy- $4^{\prime}$-hydroxy-trans-stilbene (4'$\mathrm{OH}), \quad 3,5$-dihydroxy-4'-methoxy-trans-stilbene (3,5-OH), 3, $\quad$ ' -dihydroxy-5-methoxy-transstilbene $\left(3,4^{\prime}-\mathrm{OH}\right), \quad 4^{\prime}$-amino-3,5-dihydroxytrans-stilbene ( $4^{\prime}$-amino), and $m$-hydroquinone (m-OH) $(1$ or $10 \mu \mathrm{M})$, and cell viabilities were determined. (D) Cells were cultured with resveratrol or its derivatives ( 1 or $10 \mu \mathrm{M})$ in the presence of doxorubicin ( $5 \mathrm{~nm}$ ), and cell viabilities were determined. Data are expressed as mean \pm SD, and differences were considered statistically significant at a $p$ value of $<0.05$. In all experiments, the result is representative of three independent experiments.
We determined the effects of resveratrol or its derivatives (Fig. 2A) on cell viability in the presence or absence of doxorubicin. Doxorubicin decreased cell viability at a concentration of $10 \mathrm{nM}$, but had no influence on cell viability at a concentration of $5 \mathrm{nM}$ (Fig. 2B). Resveratrol and its derivatives at concentrations of 1 and $10 \mu \mathrm{M}$ had no influence on cell viability (Fig. 2C). However, in the presence of $5 \mathrm{~nm}$ doxorubicin, cell viability was repressed to a similar degree by resveratrol, 3,5-dihydroxy4'-methoxy-trans-stilbene, 3,4'-dihydroxy-5-methoxytrans-stilbene, and 4'-amino-3,5-dihydroxy-trans-stilbene individually at concentrations of 1 and $10 \mu \mathrm{M}$ (Fig. 2D). However, 3,5-dimethoxy-4'-hydroxy-trans-stilbene and the $m$-hydroquinone moiety of resveratrol (resorcinol) had no influence on cell viability. These results indicate that resveratrol enhances the potential of the anticancer drug doxorubicin in MCF-7 cells.

We assessed the effects of resveratrol on the activity of CBR 1 using doxorubicin as a substrate. The $\mathrm{IC}_{50}$ of resveratrol on CBR1 activity was estimated to be approximately $140 \mu \mathrm{M}$. When the effects of resveratrol derivatives on CBR 1 activity were determined, CBR1 activity was inhibited to a similar degree by resveratrol, 3,5-dihydroxy-4'-methoxy-trans-stilbene, 3,4'-dihydroxy-5-methoxy-trans-stilbene, and 4'-amino3,5-dihydroxy-trans-stilbene, each at concentrations of 100 and $200 \mu \mathrm{M}$ (Fig. 3). In contrast, 3,5-dimethoxy4 -hydroxy-trans-stilbene and the $m$-hydroquinone moiety of resveratrol (resorcinol) had no influence on CBR1 activity. These results indicate that the moiety with 3,5-dihydroxyl groups of resveratrol is required as the binding site or binding spatial structure to bind CBR1, perhaps through either one of the 3,5-dihydroxyl groups.

To characterize the mechanism by which resveratrol inhibits CBR1, we examined the enzyme kinetics parameters. Resveratrol inhibited the activity of CBR1 in a concentration-dependent manner, and the lines for each inhibitor concentration crossed on the left of the $Y$-axis on the Lineweaver-Burk plots (Fig. 4A), indicating that 


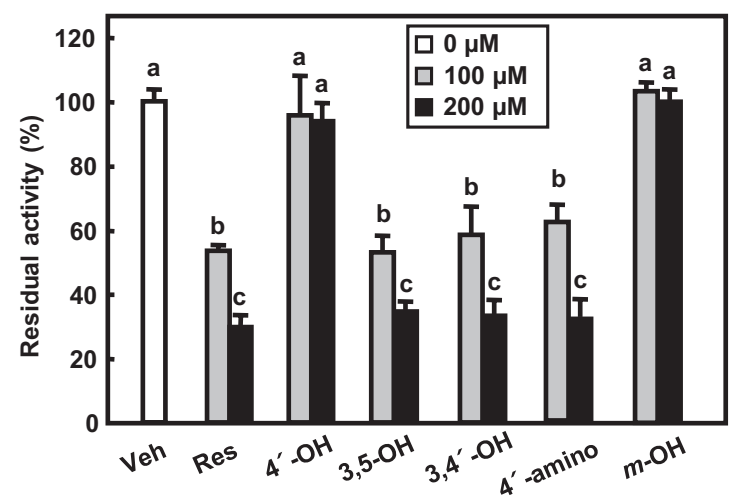

Fig. 3. Inhibition of CBR1 activities by resveratrol and its derivatives with doxorubicin. CBR 1 activities were determined in the presence of vehicle (Veh), 3,4',5-trihydroxy-trans-stilbene (Res), 3,5-dimethoxy-4'-hydroxytrans-stilbene $\left(4^{\prime}-\mathrm{OH}\right), 3,5$-dihydroxy-4'-methoxy-transstilbene $(3,5-\mathrm{OH}), 3,4^{\prime}$-dihydroxy-5-methoxy-trans-stilbene $\left(3,4^{\prime}-\mathrm{OH}\right), 4^{\prime}$-amino-3,5-dihydroxy-trans-stilbene $\left(4^{\prime}\right.$-amino), and $m$-hydroquinone $(m-\mathrm{OH})$. Data are expressed as mean $\pm \mathrm{SD}$, and differences were considered statistically significant at a $p$ value of $<0.05$. The result is representative of three independent experiments.

resveratrol acts on CBR1 activity as a mixed-type inhibitor when using doxorubicin as a substrate (Fig. 4B). To calculate Ki and $\alpha$, the slope and the intercept of the Lineweaver-Burk lines for concentrations of resveratrol as an inhibitor were plotted as a function of inhibitor concentration (Fig. 4C). The intersections of the lines from slope and intercept with the $X$-axis show $\mathrm{Ki}(55.8 \pm 12.0 \mu \mathrm{M})$ and $\alpha \mathrm{Ki}(164 \pm 51.5 \mu \mathrm{M} ; \alpha=2.98 \pm 0.98)$, respectively. Furthermore, the Lineweaver-Burk plots showed a Km value of $158 \pm 40.1 \mu \mathrm{M}$, indicating an $\alpha \mathrm{Km}$ value of $448 \pm 44.0 \mu \mathrm{M}$. These results indicate that the affinity of the CBR1-doxorubicin complex for resveratrol is approximately 3-fold lower than that of CBR1 for resveratrol and that the affinity of the CBR1-resveratrol complex for doxorubicin is approximately 3 -fold lower than that of CBR1 for doxorubicin.

\section{Discussion}

There is increasing evidence that resveratrol has health benefits. Although resveratrol is speculated to exert diverse biological functions through specific cellular mediators such as proteins, few proteins have been shown to bind directly to resveratrol. In the present study, we developed a resveratrol-affinity resin as a tool to search for and analyze specific cellular mediators of resveratrol. The resveratrol-affinity resin was prepared by binding the $4^{\prime}$-amino group of $4^{\prime}$-amino-3,5-dihydroxy-trans-stilbene to Sepharose. CBR1 must interact with 3,5-dihydroxyl groups of resveratrol to physically interact with resveratrol. Another resveratrol-affinity resin was prepared by immobilizing any one of three hydroxyl groups of resveratrol on agarose $(15,16)$. That resin bound quinone reductase 2 (15), glutathione sulfotransferase- $\pi$, and $\operatorname{ER} \beta$ (16). The interaction between resveratrol and $\mathrm{ER} \alpha$, which is in the same protein fam-
(A)

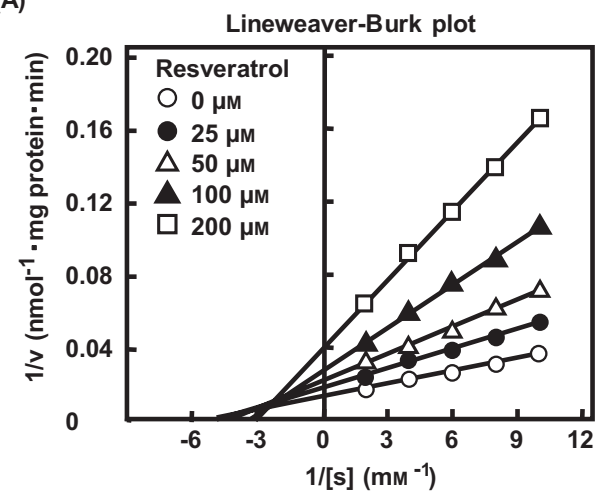

(B)

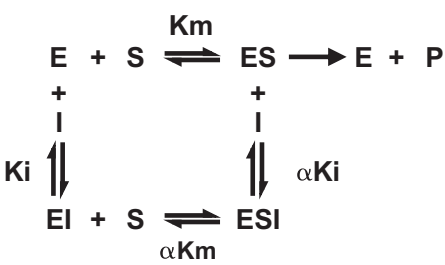

(C)

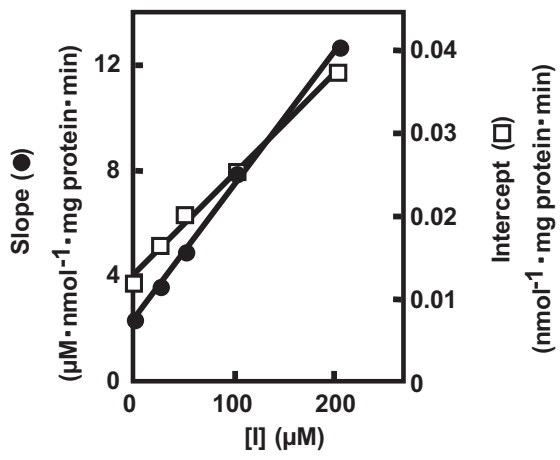

Fig. 4. Kinetics analysis of CBR1 inhibition by resveratrol. (A) CBR1 activities using the substrate doxorubicin were determined in the presence of various concentrations of resveratrol. For each concentration of resveratrol, the inverse of the velocity is plotted as a function of the inverse of substrate concentration. (B) Schematic representation of the inhibitory mechanism is shown. (C) The slope (closed circle) and the intercept (open square) of the Lineweaver-Burk representations are plotted as a function of the inhibitor concentration. The result is representative of three independent experiments.

ily as $\operatorname{ER} \beta$, requires the $4^{\prime}$-hydroxyl group of resveratrol (12). This, together with result that $\mathrm{ER} \beta$ did not bind to our resin, indicates that the present resveratrol-affinity resin provides the structural orientation needed to bind resveratrol-binding proteins because the proteins that bind to resveratrol on the resin are variable depending on how the resveratrol is bound to the resin.

CBR1 catalyzes the conversion of doxorubicin to its cardiotoxic metabolite doxorubicinol. Mice with a null allele of CBR1 are protected from doxorubicinolinduced cardiotoxicity (24), indicating that CBR1 is the main enzyme responsible for the doxorubicinol formation. Therefore, it is expected that the inhibition of CBR1 activity will improve the cardiotoxic side effect of doxorubicinol and increase the therapeutic efficacy of 
doxorubicin against tumors in patients during chemotherapy. The present study demonstrates that resveratrol at concentrations of 1 and $10 \mu \mathrm{M}$ inhibits the growth of MCF-7 cells in the presence of $5 \mathrm{nM}$ doxorubicin although $10 \mu \mathrm{M}$ resveratrol alone or $5 \mathrm{nM}$ doxorubicin alone has no influence on cell viability. Likewise, Osman et al. (9) reported that cytotoxicity of doxorubicin is enhanced by resveratrol at a concentration of $66 \mu \mathrm{M}$ although the viability of MCF-7 cells is determined under experimental conditions different from the present study. Thus, combined treatment with resveratrol and doxorubicin is effective in inhibiting the growth of MCF-7 cells, compared to treatment with doxorubicin alone. These results suggest that resveratrol increases the chemosensitivity of MCF-7 cells to doxorubicin by inhibiting CBR1 activity.

The finding that resveratrol inhibited CBR1 activity on doxorubicin with a mixed-type inhibition (Fig. 3) indicates that the inhibition involves binding not only to the CBR1 but also to the CBR1-doxorubicin complex. The flavonoid rutin (25) and the semi-synthetic flavonoid 7-monohydroxyethylrutoside (26) act as a mixedtype inhibitor and a competitive inhibitor of CBR1 activity for daunorubicin, respectively, indicating that the inhibitory mechanisms by which flavonoids inhibit CBR1 activity for anthracyclines depend on the structure of the flavonoids. The $m$-hydroquinone moiety of resveratrol and the flavonoid A-ring of rutin are structurally similar. Taken together, these results suggest that the $m$-hydroquinone moiety of resveratrol contributes to the mixed-type inhibition of resveratrol for CBR1 activity. Furthermore, the effective resveratrol derivatives for cell viability exerted inhibitory effects on CBR1 activity, indicating that the hydroxyl group in the 3 or 5 position of resveratrol plays important roles in inhibiting CBR1 activity and enhancing the cytotoxicity of doxorubicin.

CBR1 catalyzes endogenous substrates such as prostaglandin E2 (17) and $S$-nitrosoglutathione (18) in addition to exogenous substrates. CBR1 activity is inhibited by 7-monohydroxyethylrutoside as a competitive inhibitor for daunorubicin and as an uncompetitive inhibitor for menadione (26). Thus, the mechanisms by which CBR1 is inhibited by certain inhibitors depend on substrates. It is of interest to determine whether resveratrol inhibits CBR1 activity for endogenous substrates.

Some flavonoids inhibit reduction of anthracyclines such as doxorubicin and daunorubicin (25-27). The $\mathrm{IC}_{50}$ values of 7-monohydroxyethylrutoside and quercetin, which is the aglycone moiety of rutin, on CBR1 activity for doxorubicin are $59 \mu \mathrm{M}$ and $43 \mu \mathrm{M}$, respectively (26), and these flavonoids seem to be more effective in inhibiting CBR1 activity than resveratrol $\left(\mathrm{IC}_{50}=140 \mu \mathrm{M}\right)$. 7-Monohydroxyethylrutoside protects against doxorubicin-induced cardiotoxicity in rats (28), and quercetin enhances therapeutic efficacy of doxorubicin in mice bearing $4 \mathrm{~T} 1$ breast cancer (29). However, these $\mathrm{IC}_{50}$ values are not physiologically achievable concentrations. On the other hand, although the $\mathrm{IC}_{50}$ values of doxorubicin for the growth of MCF-7 cells are approximately 690 to $770 \mathrm{nM}(9,30)$, the Km value of CBR1 for doxorubicin was $158 \mu \mathrm{M}$, almost identical to previous reports that the $\mathrm{Km}$ values are 287 and $226 \mu \mathrm{M}$ when recombinant CBR 1 and MCF-7 cell lysate are used to determine the kinetics of reduction of doxorubicin, respectively $(19,30)$. At this time, we have no obvious explanation for the discrepancy between the $\mathrm{IC}_{50}$ values (or the $\mathrm{Km}$ values) and the effective concentrations of resveratrol and doxorubicin against cell viability. Recombinant CBR1 might require certain factors to exert the same catalytic function as the native form of CBR1.

Other dietary components besides resveratrol have been shown to have medicinal effects. Quercetin inhibits the activity of CBR1 for doxorubicin and daunorubicin (25). Furthermore, quercetin attenuates hypoxiainduced resistance to doxorubicin in breast cancer 4T1 cells by suppressing the expression of hypoxia-inducible factor- $1 \alpha$, which is a key regulator of the transcriptional activation of hypoxia-inducible genes (29). Resveratrol, which enhances the cytotoxic effect of doxorubicin on the growth of MCF-7 cells (9), also inhibits the expression of hypoxia-inducible factor- $1 \alpha$ in human ovarian cancer cells (31) and human tongue squamous cell carcinoma (32). However, there is no evidence that quercetin or resveratrol directly interacts with hypoxiainducible factor- $1 \alpha$. The present findings suggest that resveratrol attenuates resistance to doxorubicin treatment (for example, hypoxia-induced resistance to doxorubicin) and toxicity of doxorubicin by inhibition of CBR 1 activity and by suppression of hypoxia-inducible factor- $1 \alpha$ expression. Identification of the target molecules of resveratrol should contribute to elucidating the function of resveratrol.

\section{Acknowledgments}

Both Y. I. and T. M. carried out the experiments and equally contributed to this study. A. I. and S. T. synthesized resveratrol derivatives. S. T. analyzed data of mass spectrometry. N. H., Y. N., and H. I. provided valuable advice. R. Y. contributed to the concept and design of this study. T. M. and R. Y. drafted and revised the manuscript. All authors discussed all results and commented on the manuscript.

\section{REFERENCES}

1) Rimando AM, Kalt W, Magee JB, Dewey J, Ballington JR. 2004. Resveratrol, pterostilbene, and piceatannol in vaccinium berries. J Agric Food Chem 52: 4713-4719.

2) Wang KH, Lai YH, Chang JC, Ko TF, Shyu SL, Chiou RY. 2005. Germination of peanut kernels to enhance resveratrol biosynthesis and prepare sprouts as a functional vegetable. J Agric Food Chem 53: 242-246.

3) Burns J, Yokota T, Ashihara H, Lean ME, Crozier A. 2002. Plant foods and herbal sources of resveratrol. J Agric Food Chem 50: 3337-3340.

4) Hain R, Bieseler B, Kindl H, Schröder G, Stöcker R. 1990. Expression of a stilbene synthase gene in Nicotiana tabacum results in synthesis of the phytoalexin resveratrol. Plant Mol Biol 15: 325-335.

5) Tsai SH, Lin-Shiau SY, Lin JK. 1999. Suppression of nitric oxide synthase and the down-regulation of the 
activation of NFkappaB in macrophages by resveratrol. Br J Pharmacol 126: 673-680.

6) Frémont L, Belguendouz L, Delpal S. 1999. Antioxidant activity of resveratrol and alcohol-free wine polyphenols related to LDL oxidation and polyunsaturated fatty acids. Life Sci 64: 2511-2521.

7) Ekshyyan VP, Hebert VY, Khandelwal A, Dugas TR. 2007. Resveratrol inhibits rat aortic vascular smooth muscle cell proliferation via estrogen receptor dependent nitric oxide production. J Cardiovasc Pharmacol 50: 83-93.

8) Bhat KP, Lantvit D, Christov K, Mehta RG, Moon RC, Pezzuto JM. 2001. Estrogenic and antiestrogenic properties of resveratrol in mammary tumor models. Cancer Res 61: 7456-7463.

9) Osman AM, Bauoumi HA, Al-Harthi SE, Damanhouri ZA, Elshal MF. 2012. Modulation of doxorubicin cytotoxicity by resveratrol in a human breast cancer cell line. Cancer Cell Int 12: 47.

10) Mikstacka R, Rimando AM, Szalaty K, Stasik K, BaerDubowska W. 2006. Effect of natural analogues of trans-resveratrol on cytochromes P4501A2 and 2E1 catalytic activities. Xenobiotica 36: 269-285.

11) Murias M, Handler N, Erker T, Pleban K, Ecker G, Saiko P, Szekeres T, Jäger W. 2004. Resveratrol analogues as selective cyclooxygenase-2 inhibitors: synthesis and structure-activity relationship. Bioorg Med Chem 12: 5571-5578.

12) Lappano R, Rosano C, Madeo A, Albanito L, Plastina P, Gabriele B, Forti L, Stivala LA, Iacopetta D, Dolce V, Andó S, Pezzi, V, Maggiolini M. 2009. Structure-activity relationships of resveratrol and derivatives in breast cancer cells. Mol Nutr Food Res 53: 845-858.

13) Larrosa M, Tomás-Barberán FA, Espín JC. 2003. Grape polyphenol resveratrol and the related molecule 4-hydroxystilbene induce growth inhibition, apoptosis, S-phase arrest, and upregulation of cyclins A, E, and B1 in human SK-Mel-28 melanoma cells. J Agric Food Chem 51: $4576-4584$.

14) Szewczuk LM, Penning TM. 2004. Mechanism-based inactivation of COX-1 by red wine $m$-hydroquinones: a structure-activity relationship study. J Nat Prod 67: $1777-1782$

15) Wang Z, Hsieh TC, Zhang Z, Ma Y, Wu JM. 2004. Identification and purification of resveratrol targeting proteins using immobilized resveratrol affinity chromatography. Biochem Biophys Res Commun 323: 743-749.

16) Hsieh TC, Wang Z, Deng H, Wu JM. 2008. Identification of glutathione sulfotransferase-pi (GSTP1) as a new resveratrol targeting protein (RTP) and studies of resveratrol-responsive protein changes by resveratrol affinity chromatography. Anticancer Res 28: 29-36.

17) Gonzalez-Covarrubias V, Ghosh D, Lakhman SS, Pendyala L, Blanco JG. 2007. A functional genetic polymorphism on human carbonyl reductase 1 (CBR1 V88I) impacts on catalytic activity and NADPH binding affinity. Drug Metab Dispos 35: 973-980.

18) Bateman RL, Rauh D, Tavshanjian B, Shokat KM. 2008. Human carbonyl reductase 1 is an S-nitrosoglutathione reductase. J Biol Chem 283: 35756-35762.

19) Bains OS, Karkling MJ, Grigliatti TA, Reid RE, Riggs KW. 2009. Two nonsynonymous single nucleotide polymorphisms of human carbonyl reductase 1 demonstrate reduced in vitro metabolism of daunorubicin and doxorubicin. Drug Metab Dispos 37: 1107-1114.

20) Gavelová M, Hladíková J, Vildová L, Novotná R, Vondrácek J, Krcmár P, Machala M, Skálová L. 2008. Reduction of doxorubicin and oracin and induction of carbonyl reductase in human breast carcinoma MCF-7 cells. Chem Biol Interact 176: 9-18.

21) Sun B, Hoshino J, Jermihov K, Marler L, Pezzuto JM, Mesecar AD, Cushman M. 2010. Design, synthesis, and biological evaluation of resveratrol analogues as aromatase and quinone reductase 2 inhibitors for chemoprevention of cancer. Bioorg Med Chem 18: 5352-5366.

22) Paul S, Mizuno CS, Lee HJ, Zheng X, Chajkowisk S, Rimoldi JM, Conney A, Suh N, Rimando AM. 2010. In vitro and in vivo studies on stilbene analogs as potential treatment agents for colon cancer. Eur J Med Chem 45: 3702-3708.

23) Ogawa M, Yamaji R, Higashimura Y, Harada N, Ashida H, Nakano Y, Inui H. 2011. 17 $\beta$-estradiol represses myogenic differentiation by increasing ubiquitin-specific peptidase 19 through estrogen receptor $\alpha$. J Biol Chem 286: 41455-41465.

24) Olson LE, Bedja D, Alvey SJ, Cardounel AJ, Gabrielson KL, Reeves RH. 2003. Protection from doxorubicininduced cardiac toxicity in mice with a null allele of carbonyl reductase 1. Cancer Res 63: 6602-6606.

25) Carlquist M, Frejd T, Gorwa-Grauslund MF. 2008. Flavonoids as inhibitors of human carbonyl reductase 1 . Chem Biol Interact 174: 98-108.

26) Gonzalez-Covarrubias V, Kalabus JL, Blanco JG. 2008. Inhibition of polymorphic human carbonyl reductase 1 (CBR1) by the cardioprotectant flavonoid 7-monohydroxyethyl rutoside (monoHER). Pharm Res 25: 1730-1734.

27) Kaiserová H, Simůnek T, van der Vijgh WJ, Bast A, Kvasnicková E. 2007. Flavonoids as protectors against doxorubicin cardiotoxicity: role of iron chelation, antioxidant activity and inhibition of carbonyl reductase. Biochim Biophys Acta 1772: 1065-1074.

28) van Acker FA, van Acker SA, Kramer K, Haenen GR, Bast A, van der Vijgh WJ. 2000. 7-Monohydroxyethylrutoside protects against chronic doxorubicin-induced cardiotoxicity when administered only once per week. Clin Cancer Res 6: 1337-1341.

29) Du G, Lin H, Wang M, Zhang S, Wu X, Lu L, Ji L, Yu L. 2010. Quercetin greatly improved therapeutic index of doxorubicin against $4 \mathrm{~T} 1$ breast cancer by its opposing effects on HIF- $1 \alpha$ in tumor and normal cells. Cancer Chemother Pharmacol 65: 277-287.

30) Hanusová V, Králová V, Schröterová L, Trilecová L, Pakostová A, Skálová L. 2010. The effectiveness of oracin in enhancing the cytotoxicity of doxorubicin through the inhibition of doxorubicin deactivation in breast cancer MCF7 cells. Xenobiotica 40: 681-690.

31) Park SY, Jeong KJ, Lee J, Yoon DS, Choi WS, Kim YK, Han JW, Kim YM, Kim BK, Lee HY. 2007. Hypoxia enhances LPA-induced HIF-1alpha and VEGF expression: their inhibition by resveratrol. Cancer Lett 258: 63-69.

32) Zhang Q, Tang X, Lu QY, Zhang ZF, Brown J, Le AD. 2005. Resveratrol inhibits hypoxia-induced accumulation of hypoxia-inducible factor-1alpha and VEGF expression in human tongue squamous cell carcinoma and hepatoma cells. Mol Cancer Ther 4: 1465-1474. 